\title{
Optionality in Linguistics
}

\author{
Albina A. Bilyalova ${ }^{1} \&$ Tatyana V. Lyubova ${ }^{1}$ \\ ${ }^{1}$ Kazan (Volga region) Federal University, Russian Federation \\ Correspondence: Albina A. Bilyalova, Mira Avenue, 68/19, Naberezhnye Chelny, 423800, Russian Federation. \\ E-mail: abill71@mail.ru
}

Received: June 21, 2014 Accepted: July 24, 2014 Online Published: September 28, 2014

doi:10.5539/ass.v10n20p148

URL: http://dx.doi.org/10.5539/ass.v10n20p148

\begin{abstract}
This paper presents an attempt at conducting an analysis of the notion "optionality" based on the works of experts in the given sphere. There is a certain lack of consistency in the matter of understanding and interpretation of the given phenomenon in the linguistic literature.

Some scientists mean by optionality an opportunity to substitute one synonymic word by the other without significant changes in the plane of content; others recognize ellipsis in it, while the third party-an optional combinability.

The issue of faculty has obtained the widest discussion in sinology. According to one of the theories, optionality can be studied against redundancy and economy of language means. In this case the phenomenon of optionality in the Chinese language can manifest itself on the level of phonemes, morphemes and lexemes. Functioning of grammatical markers expressing aspect, tense, number, etc. can serve as an example, as it possesses the property of optionality.

The majority of scholars agree that optionality is an objective property of language system and is closely connected with the process of the language ongoing development.
\end{abstract}

Keywords: optionality, obligatoriness, grammatical redundancy, quasioptionality, optional morphological markers

\section{Introduction}

The dictionary of foreign languages provides the following definition of the word "optional" (French "facultatif"): "optional"-not obligatory, free to choose. The research article presents the analysis of the works of those scientists who specialize in the study of isolating and agglutinating languages, for these are the types of languages where manifestation level of this language phenomenon is the highest.

Optionality is widely represented in isolating languages. In linguistics, there are many works devoted to the optionality in languages of Southeast and East Asia (William, 1967; Solntcev, 1982). Optional ergativity in Trans New Guinea (TNG) languages has received significant recent attention (Christensen, 2010; Hynum, 2010; McGregor, 2010; Rumsey, 2010; Suter, 2010).

Linguists differ on interpretation of the phenomenon of optionality. Some scientists mean by optionality an opportunity to substitute one synonymic grammar wordform by the other without significant changes in the plane of content (Bilyalova, 2010, 2012); some recognize ellipsis in it (McGregor, 2013; Fry, 2003) or an optional combinability (Kittila, 2005), while others investigate optionality in close connection with language variation (Biber et al., 2001). Moreover, some linguists are prone to denying a possibility of optional use of language means, since they believe that optionality acknowledgement leads to revision of the general theory in the sphere of specific grammatical categories and word definition (Bykova, 1982). Nevertheless, it seems impossible to deny the existence and functioning of the optionality phenomenon. In this respect we completely agree with N.V. Solntseva who states that "optionality is an objective phenomenon determined by peculiarities of the language structure and development" (Solntseva, 1963). Such controversy breeds necessity to analyze the phenomenon of optionality itself, as well as its various manifestations depending on a language system type, clarification of optional usage of language means and delimitation of optionality and quasi-optionality.

\section{Methodology}

There is a certain lack of consistency in the matter of understanding and interpretation of the given phenomenon 
in the linguistic literature. The term optionality is used differently by different scholars in a variety of ways in the literature, some quite inconsistent, and it is not always clear in what sense of the term a particular item is optional. This paper presents an attempt at conducting an analysis of the notion "optionality" based on the works of experts in the given sphere. The authors' views in the works that we have presented here do not always coincide which proves the lack of development and divisiveness of the issue. However, we do hope that review of the academic literature will give us an opportunity to get a summary researchers' insight of this argumentative subject.

\section{Results}

Therefore, it can be stated that the issue of optionality finds its certain solution in the works of researchers of the Chinese, Vietnamese, Mongolian and other languages.

In our point of view, the issues concerning optional usage of language elements on different language levels are to this or that extent researched; the majority of scholars agree that optionality is an objective property of language system and is closely connected with the process of the language ongoing development. We do hope that the questions outlined in the article throw light on the particular instances of optionality selected for discussion.

\section{Discussion}

The issue of optionality seems to appeal to scholars in the sphere of any language. As far as we are concerned, the issue of faculty has obtained the widest discussion in sinology. In the 1930s, a French scientist A. Maspero put forward an idea based on existence of the phenomenon of optionality in the language. According to his conception, formal language elements are used absolutely subjectively in the speech; in other words, optionality of formal markers usage has an absolute nature in the Chinese language. However, further research of formal markers usage regularity in the Chinese language did not confirm A. Maspero's views concerning absolute nature of optionality. The term "optionality" gained widespread currency in the late 1950s in the works of European scientists devoted to description of isolating languages. It is also necessary to mention that domestic scientists started studying the phenomenon of optionality in detail rather recently, at the end of the 1970s-beginning of the 1980s. Once again, it should be pointed out that linguists do not have a uniform, clear definition of the phenomenon of optionality.

Thus, a sinologist A. L. Semenas studies optionality against redundancy and economy of language means. He comes to a conclusion that the phenomenon of optionality in the Chinese language can manifest itself on the level of phonemes, morphemes and lexemes. As an example A. L. Semenas points to the functioning of grammatical markers expressing aspect, tense, number, etc., as their functioning possesses the property of optionality. This quality means that in certain grammatical and semantic conditions the presence or absence of a marker doesn't cause change of meaning. A. L. Semenas pays a special attention to one of them. In the Chinese language the notion of plurality can be expressed in different ways: reduplication, generalizing words, affixation, and lexical means. It is enough to use one of the ways to express plurality and to avoid grammatical redundancy. For example, in the sentence Qítā duìyuán dōu qù shàngbānle, jiù zhǐ zài zhèlǐ de chúshī "The other team members have gone to work, there's only the cook here"-the word "team members" is used here without a signal of plurality, as the meaning of plurality is already expressed by the generalizing word "everybody" and pronoun "the others". In other words, usage of the plurality signal of the noun is redundant, hence the form team members + a signal of plurality is optional. The scientist believes that redundancy of language expression means and optionality of their usage are interconnected. Moreover, he underlines that redundancy is an indispensable condition for optionality. But let us point out that high level of redundancy does not always lead to frequent optionality manifestation. The Russian language can serve as an example of this, as redundancy is more frequent there than in the Chinese language. Nevertheless, the optionality phenomenon happens more often in the Chinese language. As it turns out, language means redundancy creates conditions for optionality, but its manifestation is determined by the language grammar structure as well as those grammatical means that it uses. Thus, in the Russian language the category of number is expressed not only in the noun itself but is also repeated in the coordinating adjective and verb: for example, Green grasshoppers are hiding in the green grass (by V.V. Bianca). It is not quite possible to imagine a Russian word out of category of number (Green grasshoppers are hiding). Taken out of context, it still normally has either singular or plural form. In the Chinese language plural form is usually expressed only once, for example, in a noun. If there is a marker of plurality in a sentence (through a numeral, adverb or situation), then, in order to avoid grammatical redundancy the affix-men can be omitted. To express plurality it is enough to use one of the ways, and, verb or adjective does not have a plural form that coordinates with noun, unlike in case of inflectional languages. A. L. Semenas notes that in any language in the 
world there is a tendency to language means economy on all language levels, which, according to his words, leads to the fact that "the phenomenon of optionality reflects a constant struggle between redundancy and tendency towards language means economy. When the latter wins, the usage of some elements becomes optional, so they can fall out of the language form functioning system" (Semenas, 1982).

A sinologist S. B. Yankiver, who studied optionality in the Chinese literary language, considered language elements optionality in comparison with obligatoriness. He writes in his article "Revising the issue of optionality and obligatoriness in the Chinese language": "In the modern Chinese literary language, as well as in other isolating languages of the Far East and South-East Asia, the usage of some auxiliary parts of speech (inflectional suffixes and auxiliary words), functioning in morphology and syntax, is not obligatory in a number of cases" (Yankiver, 1982). He emphasizes that the presence of such auxiliary elements does not influence the meaning and establishing grammatical links between content words in a simple sentence or between the parts of complex sentence. He calls such auxiliary elements optional, and the corresponding phenomenon-optionality. On morphological level, S. B. Yankiver gives an example of the absence of the perfective aspect in telic verbs; omission of a suffix or a constructive word which is a signal of continuous aspect; as well as omission of a suffix indicating collective plurality. The author of the article includes with optional syntactical auxiliary words such prepositions as czai "in",dan 'in', ihou 'after', auxiliary word dy serving for the connection between the main and auxiliary members of a nominative phrase; as well as subordinating conjunction yaoshi "if", coordinating conjunction bintce "besides", "along with this", "as well as"; phrasal particles dy, ma, contributing to a sentence a modal meaning of reality, authenticity of a message, and the interrogative meaning; as well as some other auxiliary words. He provides examples proving the fact that deletion or omission of the above mentioned auxiliary words does not lead to a change or disturbance of grammatical links. As it has been mentioned above, S. B. Yankiver views optinality in connection with obligatoriness. He considers optionality of auxiliary elements to be only possible against the backdrop of obligatoriness. It is also emphasized that "there are no such auxiliary elements, whose disuse is acceptable under any conditions. An auxiliary element, which is facultative in some conditions, is obligatory in others" (Yankiver, 1982). For instance, suffix-la, building the perspective aspect form, is obligatory with non-terminative verbs and facultative with telic verbs. Like A. L. Semenas, S. B. Yankiver views redundancy as a precondition for optionality. Besides, he points to the fact that optionality and obligatoriness live in certain dependence on the phenomenon of redundancy; in other words, provided that auxiliary element usage is redundant, plus certain duplication takes place, it creates conditions for its optional usage. In morphology an inflectional marker is redundant when one and the same meaning is expressed twice: by a grammatically inflectional marker and lexical-grammatical meaning of a verb it refers to. Let us analyze the following sentence: Zai yesyaole dou czyaoshi yun putongczyaosue. "At an evening school all teachers hold classes in Putonghua" (Putonghua is a national Chinese literary language unlike dialects). Here the noun denoting a lot of individuals "teachers" is not completed by the plurality affix, because the meaning of plurality is expressed by the word 'all'. In syntax an auxiliary is redundant when one and the same communication type is served by two grammatical means at the same time, one of which is the given auxiliary word; or when a meaning added to a sentence by a particle is expressed by another grammatical or lexical means. S. B. Yankiver also underlines the necessity of delimitation of auxiliary elements and the impossibility of their usage (false optionality or quasi-optionality). He correctly supposes that if a missing auxiliary element can be restored, its usage is optional; if it is impossible to restore it and particle ды is not duplicated, it is the example of quasi-optionality.

The issue of optionality in national linguistics is exposed to light in the works of most leading researchers of isolating languages, Chinese in particular, linguists and a married couple V. M. Solntsev and N. V. Sontseva. The following works should be mentioned: "Sketches on modern Chinese language", "On the "zero" and "absolute" form in the Chinese language", "Language as a system-structural phenomenon", "Theory of optionality and the issue of an unmarked verb form", "Nature of morphological categories in the Chinese language" etc. In his article "On the notion of "optionality" V. M. Solntsev notes that optional elements and phenomenon are normally grammatical, not lexical (Solntsev, 1982). Speaking of lexical elements, ellipsis and in some cases synonymy can be regarded as optionality. The scientists solve the issue with reference to the Chinese language, where, as we have more than once noted, free usage of this or that marker is often observed in the sphere of morphology. Let us analyze the following two sentences: Ta czotyan lajla and Ta czotyan laj "He came yesterday". The omission of the suffix-la in the verb "to come" does not change either the general meaning of the sentence or its grammatical links. So, the notion of optionality is defined by V. M. Solntsev as a special quality of morphological markers, which is manifested when the meaning corresponding with the given marker is expressed in some other way. Thus, a whole phrase (sentence) reveals not the proper meaning of an omitted marker which is eliminated if a marker is omitted (there is a marker-there is meaning; no marker-no 
corresponding meaning), but some general meaning, to express which the given marker can also be used. Proceeding from the aforesaid, optionality can be defined as a situation in language when a marker may be used or not used without obviously visible reasons. In this connection the scientist provides the abovementioned example of la-suffix omission in the sphere of morphology. It does not change either grammatical word links or general meaning of the sentence. Ta czotyan lajla-Ta czotyan laj 'he came yesterday'. And in the sphere of syntax-there is a case of preposition omission zai in the prepositional-postpositional construction zai zhuozi shang ben shu-zhuozi shang ben shu "There is a book on the table". In both cases different means (in the first case-grammatical; in the second-lexical) create conditions for marker redundancy, and redundancy, in its turn, becomes a reason for optional usage of a morphological marker or preposition.

Definition V. M. Solntsev gives to the phenomenon of optionality appears to be most complete and extensive. He writes: "By optionality one can understand freedom (or possibility) of omission or, on the contrary, usage of this or that language element in a speech chain within the limits of a word, phrase or sentence, or change of language elements order under two conditions: a) no change of grammatical relations among language elements in a speech chain; b) no visual change of meaning" (Solntsev, 1982). Finally, V. M. Sontsev comes to the following conclusion: as a whole, optionality can be defined as a peculiarity of language elements functioning, which is manifested under following conditions: 1) optional elements of language are most often grammatical; 2) morphological markers, in order to be optional, must be of non-syntactic nature; 3) syntactic optionality (for instance, word order freedom) is only possible at presence of morphological markers of syntactic nature, that is pointing to word connection in the speech. Other types of syntactic optionality are possible provided there is another redundancy-creating syntactical means; 4) in a number of cases a condition for optionality is redundancy of some general meaning expression means; 5) in isolating languages morphological optionality is, in particular, determined by relative youth of morphological markers and specificity of language morphological structure.

In N. V. Solntseva's point of view, the essence of the given phenomenon is in its potential possibility to easily use grammatical elements as a quality of some of them, as well as in conditions and reasons leading to realization and not realization of optionality of such elements. In the article "Revising the issue of optionality" she writes: "It is the optionality quality of forms and categories that leads to wide usage of various language means for expression of some general meaning which only to some extent correlates with grammatical meanings" (Solntseva, 1963).

Among the scholars who studied Indo-European languages, Y. A. Rubinchik is the one that dealt with the issue of optionality in the Persian language. Conducting research on the Persian language he came to the conclusion that optionality in this language manifests itself as omission of prepositions expressing spatial relationships (directions, locations); as omission of pronouns in two-member sentences where a subject is expressed by a personal pronoun (in the Russian language there is a similar phenomenon). The optionality phenomenon can also be observed on the lexical level when analyzing the usage of some Persian affixation morphemes. There are cases of optionality on the phonemic level too. While Y. A. Rubinchik views optionality phenomenon as irregularity of grammar markers usage, he also pays a lot of attention to the reasons for language means optional usage. As main reasons he counts the rule of language means economy (the language tendency towards expression of identical meanings in the shortest way possible) as well as the rule of differences neutralization when the weak (or unmarked) member out of two neutralized elements takes a general function. Y. A. Rubinchik also notes that "optionality in the language is not a manifestation of total choice freedom of this or that means (or a way) for expression of identical meaning and does not completely depend on subjective will of the speaker or writer. With a large context the choice of means and ways for expressing one and the same meaning gets greatly reduced. It is normally possible to explain reasons for usage or omission of an optional element. That is why all-round study of optionality is necessary not only for specification of the term but also for a better understanding of reasons and conditions contributing to its occurrence" (Rubinchik, 1982). It is hard to disagree with the statement.

Linguist L. N. Kisilyova also pays attention to the language phenomenon-optionality in her works. In the article "A few remarks on the issue of optionality", while researching optionality usage of language means in the Dari language, she points to the fact that optionality should be noticed in connection with the variants of language units (phonemes, morphemes, words, constructions) that take place in the process of their realization in the speech (Kisilyova, 1982)]. Thus, the scholar makes the strong connection between optionality and variability, referring to the definition of optionality given by such scholars as O. S. Akhmanova, who, while defining the terms "optional phoneme" and "optional variant" opposes them to the notion of constrained, position-dependent variant (Akhmanova, 2014); as well as French linguist J. Maruso. He wrote in his dictionary of linguistic terms: "Variants are called optional when their occurrence does not depend on the context or is not a necessary result of 
the context (for instance, apical variant of $\mathrm{R}$ in the French and German languages) (Maruso, 2004). In the Dari language the sentence "Soma ce gofted" "What did you say?" has grammatical redundancy: the category of person and number is expressed twice there (with the help of the pronoun and verb form). Alongside with this, another (elliptical) construction without the personal pronoun is acceptable in the speech: Ce gofted 'What did (you) say?'. L. N. Kisilyova underlines that the speaker is free to choose between these two alternative constructions, hence, it is possible to speak about optional usage of personal pronouns with the personal verb forms in the Dari language. As variation is typical of all the levels and layers of the language system, L. N. Kisilyova, like A. L. Semenas, acknowledges the issue of optionality to be important for all levels. Quite a number of aspects of language signs functioning, as well as such language phenomena as redundancy, ellipsis, parallelism, alternation, and substitution can be narrowed down to variation, this way or the other. However, is optionality common for all these phenomena? To answer this question, L. N. Kisilyova suggests defining conditions and pre-conditions, where optionality manifests itself. She considers alternative or, in other words, choice of variants to be the main pre-condition. The presence of one or two variants of language elements or language phenomena between which the speaker can choose makes it possible to speak about manifestation of optionality in the language. L. N. Kisilyova then makes a peculiar conclusion that optionality is a temporary language phenomenon that is this phenomenon is unstable. She believes that, just as there are no full synonyms, there are no absolute variants of reproduction. Concerning those that are optional at the given moment of speech, it can be stated that they were not always so. Choice freedom is relative; moreover, it is completely removed in case of historical approach. Hence, optionality is a completely static phenomenon, which makes it temporal and disappearing in the process of language development.

Another scholar T. Y. Yelizarenkova, conducting research of the language in diachrony, namely the developmental history of the ancient Indian language, mentions in her article "On optionality and its peculiarities in the ancient Indian language" that optionality can be considered as a means to provide additional channels of the language functioning, as a kind of backup that performs merely stylistic function under the certain language conditions, but being able to become the major one in case of language modification. The scholar gives the following definition to the optional language phenomena: "In every synchronic condition a speaker and a writer has a choice thanks to optionality. This does not only enlarge informative power of language but also gives the opportunity to make an intralingual translation and metalinguistic operations that language cannot exist without" (Yelizarenkova, 1982). T. Y. Yelizarenkova believes that analysis of optionality issue is closely connected with the issues of language styles. She writes: "As it is important for modern linguistics to underline inextricable connection of language and emotive language and consideration of language in more than one function, the issue of norm-optionality is solved ambivalently in the language and only regarding this or that style that the given language system is presented with. What is a norm for one style of the given language may be an optional variant for the other. In other words, there is always a binary (or, to be more precise, more than one) system of expression in the language". For instance, in the Russian literary language the pronunciation norm for the word "now" is $[s i t / \Lambda s]$ and the optional pronunciation is [fess]. On the contrary, in the informal spoken language the obligatory variant is pronunciation [ [ ces] , whereas the optional variant is [sit/As].

E. M. Bykova who researched Bengali, which belongs to the group of agglutinate languages, admits the existence of optionality in the language as an opportunity of usage-not usage of an auxiliary element of a grammatical unit. E. M. Bykova writes in her article "Optionality?": "This opportunity is one of the peculiarities of flexionless languages, in the grammatical structure of which agglutination takes the leading role; besides, potential usage and omission of an element of the given grammatical structure occurs quite often" (Bykova, 1982). Further in her article, while analyzing optionality manifestation in Bengali, E. M. Bykova pays attention to the following language phenomenon: the noun has singular and plural forms in Bengali; besides, plurality expression means can be various, namely with the help of affixation, phrase or context. To express plurality of individuals or objects denoted by the noun it is enough to resort to one of these means. The author of the article provides the following example. In Bengali plurality of the noun is manifested through suffixes-d,-guli,-ra etc. For instance: Rikfawala fontorpone mor ghuriye nəy te rastar mor theke 'At the crossroads the rickshaw men turned round the corner'. The noun Rikfawala lacks the plurality affix. The point is the sentence was preceded by another sentence where it was stated that there were a lot of rickshaw men. As the context makes it clear that the noun is plural, the usage of plurality affix in the next sentence becomes redundant (it is expressed by the context); thus, the noun form rikfawala in this example can be regarded as optional. By this the scholar acknowledges the existence of optionality in the choice of this or that form. In conclusion, E. M. Bykova states that optionality in the grammatical structure of language does not play a key role; she then encourages linguists to pay less attention to this phenomenon while describing languages, because to her mind the most important in any language is its norms. 


\section{Conclusion}

Based on the above stated, a diverse assessment of optionality use extent, various accounts for the occurrence of language markers optionality use, as well as absence of universal definition of optionality phenomenon are the result of certain disagreement in understanding of the essence of this language phenomenon and need further research. The proposals of this paper raise numerous issues for further investigation.

Despite a certain controversy in understanding the notion of optionality, we believe that the article can contribute to better understanding of one of the ambiguous but quite remarkable and unique language phenomena. There is no doubt that factual data concerning various realization of optionality in the languages of different typology considerably advance the solution of the issue, both in methodological and academic-and-research terms.

\section{References}

Akhmanova, O. S. (2014). Glossary of linguistic terms (p. 607). Moscow.

Biber, D., \& Conrad, S. (2001). Register variation: A corpus approach. In D. Schriffin, D. Tannen, \& H. E. Hamilton (Eds.), The handbook of discourse analysis (pp.175-197).

Bilyalova, A. A. (2010). Optionality: Trend or error. Teacher of XXI century, 4, 301-307.

Bilyalova, A. A. (2012). Some cases in the use of non-obligatory forms in English. Materials of the 8-th International scientific and practical conference "Бъдещето въпроси от света на науката" (pp. 11-15). Sofia.

Bykova, E. M. (1982). Optionality? East Linguistics: Optionality (pp. 13-20). Moscow: Nauka.

David, H. (2010). Ergative in Numanggang. In J. Hooley (Ed.), Papers on six languages of Papua New Guinea (pp. 129-156). Pacific Linguistics 616 (pp. 56-129). Canberra: Australian National University.

Elizarenkova, T. Y. (1982). On optionality and its features in the ancient Indian language. East Linguistics: Optionality (pp. 33-41). Moscow: Nauka.

John, F. (2003). Ellipsis and wa-marking in Japanese conversation. New York \& London: Rouledge.

Kisileva, L. N. (1982). Some remarks on the issue of optionality. East Linguistics: Optionality (pp. 43-47). Moscow: Nauka.

Maruso, J. (2004). Glossary of linguistic terms (p. 442). Moscow.

Matthews, P. H. (2007). The concise Oxford dictionary of linguistics (p. 245). Oxford University Press.

McGregor, W. B. (2010). Optional ergative case marking systems in a typological-semiotic perspective. Lingua, 120(7), 1610-1636. http://dx.doi.org/10.1016/j.lingua.2009.05.010

McGregor, W. B. (2013). Optionality in grammar and language use. Linguistics, 51(6), 1147-1204. http://dx.doi. org/10.1515/ling-2013-0047

Rubinchik, Y. A. (1982). On narrow and broad understanding of optionality. East Linguistics: Optionality (pp. 74-78). Moscow: Nauka.

Rumsey, A. (2010). "Optional” ergativity and the framing of reported speech. Lingua, 120, 1652-1676. http://dx. doi.org/10.1016/j.lingua.2009.05.012

Semenas, A. L. (1982). On optionality and redundancy in Chinese. East Linguistics: Optionality (pp. 87-91). Moscow: Nauka.

Seppo, K. (2005). Optional marking of arguments. Language Sciences, 27, 483-514. http://dx.doi.org/10.1016/j. langsci.2004.10.005

Solntcev, V. M. (1982). On the concept of "optionality". East Linguistics: Optionality (pp. 92-102). Moscow: Nauka.

Solntseva, N. V. (1963). Theory and problems of optionality unmarked verb forms. Controversial Issues grammar of the Chinese language, 7-14.

Steve, C. (2010). Yongkom discourse: Ergativity and topic. Papers on six languages of Papua New Guinea, Pacific Linguistics 616 (pp. 1-39). Canberra: Australian National University.

Suter, E. (2010). The optional ergative in Kâte. In J. Bowden, N. P. Himmelmann, \& M. Ross (Eds.), A journey through Austronesian and Papuan linguistic and cultural space: Papers in honour of Andrew Pawley. Pacific Linguistics 615 (pp. 37-423). Canberra, Australia. 
William, S. Y. W. (1967). Bibliography of Chinese linguistics (pp. 188-499).

Yankiver, C. B. (1982). On the optionality and obligatoriness in Chinese. East Linguistics: Optionality (pp. 144-150). Moscow: Nauka.

\section{Copyrights}

Copyright for this article is retained by the author(s), with first publication rights granted to the journal.

This is an open-access article distributed under the terms and conditions of the Creative Commons Attribution license (http://creativecommons.org/licenses/by/3.0/). 